Revista de

Contabilidade e Organizações
DOI: http://dx.doi.org/10.11606/issn.1982-6486.rco.2018.147269
Journal of

Accounting and

Organizations

\title{
Habilidades matemáticas e o conhecimento financeiro no ensino médio
}

Mathematical skills and financial knowledge in high school

Marcella Alves da Silva a; Edvalda Araujo Leal ${ }^{\text {; }}$; Tamires Sousa Araújo ${ }^{a}$

${ }^{a}$ Universidade Federal de Uberlândia

Palavras-chave

Ensino médio.

Educação Financeira.

Conhecimento Financeiro.

Habilidades Matemáticas.

\begin{abstract}
Resumo
A educação financeira é essencial no cotidiano dos jovens brasileiros para planejar um consumo mais consciente. $\mathrm{O}$ artigo discute a associação do conhecimento financeiro dos estudantes do ensino médio de escolas públicas em uma região metropolitana com características demográficas e socioeconômicas de cerca de 970 jovens. A pesquisa foi aplicada para os jovens distribuídos em oito escolas públicas de diferentes regiões da cidade, e foi medido o conhecimento financeiro pelas respostas incorretas dadas em temáticas como juros e descontos, valor do dinheiro no tempo e investimentos. Além da relação com renda familiar e gênero, usualmente encontradas já na literatura, este estudo mostra que a educação financeira tem relação direta com habilidades matemáticas dos jovens.
\end{abstract}

\begin{abstract}
Financial education is essential in the daily lives of young Brazilians to plan a more conscious consumption. This article discusses the association of the financial knowledge of high school students of public schools in a metropolitan region with demographic and socioeconomic characteristics of about 970 young people. The research was applied to the adolescents enrolled in the eight public schools of different regions of the city, and the financial knowledge was measured by the incorrect answers given in themes such as interest and discounts, time value of money and investments. In addition to family income and gender, usually already listed by the literature, this study shows that financial education has a direct relation with the mathematical skills of young people.
\end{abstract}

\section{Implicações práticas}

O baixo domínio da educação financeira entre os jovens estudantes, evidenciados na pesquisa, contribuem para reforçar a necessidade de inclusão de políticas públicas ou iniciativas privadas que auxiliem os jovens a planejarem suas finanças pessoais, de modo a contribuir para uma eficiente administração dos recursos financeiros pessoais e familiares.

\section{INTRODUÇÃO}

A preocupação acerca do entendimento por parte do indivíduo sobre finanças pessoais é uma tendência mundial. Em vários países no mundo, com o respaldo da Organização das Nações Unidas (ONU), governo e sociedade se organizam com o fim de distribuir informações de finanças pessoais à população, sobretudo, por meio de projetos de alfabetização financeira, como, por exemplo, incluindo-a no currículo escolar (Vieira, Bataglia \& Sereia, 2011). 
As decisões financeiras se tornaram complexas e, por isso, alguns aspectos passam a ter relevância, tais como: as crianças e adolescentes a se preocuparem em como gastarão as mesadas; os jovens ingressam no mercado de trabalho e passam a receber salários, o que demanda certa precaução para que sejam bem aplicados; os adultos buscam aumentar seu patrimônio e planejar a aposentadoria; e os idosos começam a demonstrar certa inquietude diante da incógnita de como se manterão, estando já aposentados. A educação financeira seria importante base para direcioná-los nessas escolhas (Organisation for Economic Cooperation and Development, 2017).

Os índices de endividamento individual na sociedade brasileira estão cada vez mais altos, e indivíduos se comprometem financeiramente cada vez mais. A Confederação Nacional do Comércio de Bens, Serviços e Turismo constatou que, em 2016, 58,7\% das famílias se endividaram, o que impossibilita, por exemplo, a concretização de adquirir algum bem ou serviço em longo prazo, como também prejudica o bem-estar doméstico (Confederação Nacional do Comércio de Bens, Serviços e Turismo, 2016). Já os dados do Serviço de Proteção ao Crédito (SPC) (2016) mostram o crescimento do número de jovens nas listas de inadimplência, sendo cerca de $77 \%$ da juventude brasileira impulsiva na hora da compra, os quais se arrependem após a aquisição, pois a compra compromete seus recursos e/ou torna-se supérflua (SPC, 2016).

A educação financeira, em um contexto de endividamento crescente, auxiliaria o planejamento e um consumo mais consciente. Esta modalidade de educação influencia no processo de tomada de decisões de consumo, poupança e investimento dos jovens (Lizote, Simas \& Lanas, 2012; Vargas, 2015). Estes jovens na vida adulta carregarão essa educação financeira para garantir o bem-estar social (Gorla et al., 2016). Além dos tradicionais estudos mostrando associação de características socio-demográficas na educação financeira, alguns estudos já identificaram que o conhecimento financeiro tem forte dependência de habilidades matemáticas dos jovens (Bahrani, Holder \& Patel, 2017, Amezcua \& Everardo, 2017, Bover, Hospido \& Villanueva, 2015; Mancebón, Embún \& Sancho, 2016; Hilgerth, Hogarth \& Beverly, 2003).

O estudo pioneiro na América Latina, de Amezcua e Everardo (2017) já encontrou o mesmo efeito na Cidade do México. No nosso melhor conhecimento, tal estudo não foi feito no contexto brasileiro. O contexto brasileiro é marcado pelo nível insuficiente em matemática. Cerca de $70 \%$ dos alunos terminam o ensino médio com nível insuficiente em matemática (nível 2 de 10 níveis), segundo o Sistema de Avaliação da Educação Básica (SAEB) para o ano de 2017.

Algumas iniciativas já vendo sendo realizadas no Brasil. Por exemplo, em 2015 a Secretaria de Educação Básica (SEB) do Ministério da Educação e o Grupo de Apoio Pedagógico (GAP) implementaram um projeto piloto colocando educação financeira em escolas públicas de ensino médio no Ceará, em Minas Gerais, no Rio de Janeiro, em São Paulo, no Tocantins e no Distrito Federal. A ação distribuiu material sobre o tema para cerca de 26 mil discentes e 2 mil docentes. O Banco Mundial analisou o resultado do projeto, e detectou aumento de 1\% do nível de poupança entre estes jovens, cerca de $20 \%$ deles passaram a fazer uma lista dos gastos (consciência e priorização). Desde então o MEC tem disseminado o projeto no ensino fundamental e médio (MEC, 2015).

O presente estudo procura contribuir com a temática, estendendo o debate. O estudo identifica o nível de educação financeira dos jovens do ensino médio de escolas públicas em uma região metropolitana brasileira que passou pelo projeto piloto mencionado. Além de identificar a associação da educação financeira com características demográficas e socioeconômicas, o estudo propõe a análise das habilidades matemáticas dos jovens como um fator relevante para a educação financeira. A região escolhida foi a cidade de Uberlândia, cidade de alta concentração industrial e importante polo logístico nacional. Foi aplicado questionário para mais de 970 jovens em oito escolas públicas de diferentes regiões da cidade.

\section{EDUCAÇÃO E CONHECIMENTO FINANCEIRO}

Lusardi e Mitchell (2013) abordam que a educação financeira é a capacidade de processar informações financeiras ou econômicas para tomar decisões sobre o planejamento financeiro, poupança e dívidas (obrigações futuras).

O Banco Central (2015, p. 1) considera que “a Educação Financeira é o processo mediante o qual os indivíduos e as sociedades melhoram sua compreensão dos conceitos e produtos financeiros". Nesse sentido, a educação financeira possibilita a formação de consumidores mais conscientes dos seus gastos e mais exigentes quanto ao que o mercado tem a ofertar, visto que, conforme Remund (2010), oferece um conjunto de conhecimentos para auxiliar os indivíduos na tomada de decisões para a melhoria do gerenciamento de recursos pessoais. A educação financeira é sinônimo de conhecimento financeiro, indivíduos não educados financeiramente são compulsivos na utilização do crédito, compram de forma compulsiva, e comprometem sua capacidade de pagamento, e se endividam (Moore, 2003). 
A educação financeira torna as pessoas mais conscientes das oportunidades financeiras, das escolhas possíveis e das consequências. Dessa maneira ela ajuda a desenvolver habilidades para acumulação de riquezas, melhorando o comportamento, além de ampliar a visão de longo prazo e planejamento para que possam desfrutar de sonhos e atingir as metas desejadas (Clancy, Weiss \& Schreiner, 2001). Além disso, a educação financeira amplia a capacidade de compreensão de conceitos básicos, dá sustentação ao planejamento familiar, bem como proporciona que os indivíduos fiquem mais informados e seguros no tocante a práticas financeiras (Opletalová, 2015).

Adotar a educação financeira desde a infância é uma necessidade para ajudar indivíduos na responsabilidade de administrar os recursos próprios (Bernheim \& Garett, 2001). Os pais e a escola seriam os principais agentes disseminadores na formação em educação financeira dos estudantes do ensino médio, uma vez que, nessa fase da vida, ainda está em desenvolvimento uma formação para a construção de um adulto consciente quanto ao controle de suas finanças (Gorla et al,2016). No Brasil, a ausência da educação financeira em todas as esferas é preocupante. O país é considerado como detentor de alto desequilíbrio de renda, sendo necessárias, pois, medidas para corrigir tal distorção. São necessárias medidas de geração de conhecimento sobre o tema, que envolvam vários agentes da sociedade, como instituições públicas e privadas, bem como a escola, a fim de melhorar o conhecimento financeiro dos indivíduos (Savoia et al., 2007).

Contudo, além da influência da escola, o conhecimento financeiro presente em jovens também tem associação com características socioeconômicas. O Quadro 1 sintetiza as variáveis demográficas pesquisadas em alguns estudos nacionais e internacionais. 


\begin{tabular}{|c|c|c|}
\hline Variáveis & Relação com o Conhecimento Financeiro & Fonte \\
\hline \multirow{5}{*}{ Gênero } & $\begin{array}{l}\text { O gênero feminino apresenta mais propensão ao baixo nível de } \\
\text { conhecimento financeiro. }\end{array}$ & Potrich, Vieira e Kirch (2015) \\
\hline & $\begin{array}{l}\text { As mulheres são mais inseguras que os homens ao responderem sobre o } \\
\text { mercado financeiro. }\end{array}$ & Monteiro, Fernandes e Santos (2011) \\
\hline & $\begin{array}{l}\text { O gênero masculino apresenta melhor comportamento na administração } \\
\text { de seus recursos e em cálculos financeiros. }\end{array}$ & Potrich, Vieira e Paraboni (2013) e Chen e Volpe (1998) \\
\hline & $\begin{array}{l}\text { Os indivíduos do gênero masculino têm um escore maior referente à } \\
\text { educação financeira se comparado com o gênero feminino. }\end{array}$ & Gorla et al. (2016) \\
\hline & $\begin{array}{l}\text { Estudantes alemãs e lituanas detêm maior domínio de conhecimento } \\
\text { financeiro do que os meninos. }\end{array}$ & Mavlutova, Sarnovics e Armbruster (2015) \\
\hline \multirow{3}{*}{ Idade } & Quanto mais jovens consomem mais e poupam menos. & Costa e Miranda (2013) \\
\hline & $\begin{array}{l}\text { Os mais jovens e idosos erram mais sobre questões acerca de conhecimento } \\
\text { financeiro. }\end{array}$ & Atkinson e Messy (2012) \\
\hline & A alfabetização financeira real declina em idades mais baixas. & Finke, Howe e Huston (2011) \\
\hline \multirow{3}{*}{ Renda } & $\begin{array}{l}\text { Os indivíduos que tem maiores rendas são os que detêm maiores } \\
\text { conhecimentos financeiros. }\end{array}$ & Potrich, Vieira, Ceretta (2013); Lopes et al. (2014) \\
\hline & A alfabetização financeira aumenta acentuadamente com o nível de renda. & Scheresberg (2013); Lizote e Verdinelli (2014); e Verdinelli et al. (2014) \\
\hline & $\begin{array}{l}\text { A riqueza e a alfabetização financeira são correlacionadas ao longo do } \\
\text { ciclo de vida. Baixo poder aquisitivo culmina e baixa instrução financeira. }\end{array}$ & Bottazzi, Jappelli e Padula (2011); e Sallen (2015) \\
\hline \multirow{3}{*}{ Escolaridade e influência dos pais } & $\begin{array}{l}\text { Aqueles que têm pais que já concluíram o ensino superior apresentam } \\
\text { maior domínio e seguranças sobre finanças. }\end{array}$ & Verdinelli, Lizote e Olivares (2014); e Vieira, Bataglia e Sereia (2015) \\
\hline & $\begin{array}{l}\text { Os pais e a escola são os principais meios que os estudantes adquirem } \\
\text { conhecimento sobre finanças. }\end{array}$ & Braido (2014); Verdinelli et al. (2014); e Liao e Cai (1995) \\
\hline & $\begin{array}{l}\text { Os pais influenciam significativamente o conhecimento, atitude, e } \\
\text { comportamento financeiro dos filhos. }\end{array}$ & Jorgensen (2007); e Ibrahim, Harun e Isa (2009) \\
\hline
\end{tabular}

Quadro 1. Síntese dos estudos relacionados ao Conhecimento Financeiro

Fonte: Elaborado pelas autoras. 
A seguir destaca-se alguns detalhes dos estudos apresentados no Quadro 1. Três estudos com estudantes universitários mostram baixo grau de conhecimento financeiro. O primeiro, Potrich, Vieira e Ceretta (2013) em uma amostra de 534 estudantes universitários de diferentes semestres e cursos de universidades públicas e privadas da cidade de Santa Maria, Rio Grande do Sul. Segundo, Lizote e Verdinelli (2014) com estudantes universitários em Santa Catarina. Já Jobim e Losekann (2015) mensuraram a alfabetização financeira dos estudantes universitários da Universidade da Região da Campanha, Rio Grande do Sul, utilizando duas dimensões: conhecimento e comportamento financeiro. Os autores constataram que a maioria $(37,3 \%)$ dos discentes apresenta baixo desempenho em relação ao conhecimento financeiro. Tais achados são similares aos encontrados por Potrich et al. (2013) e Potrich et al. (2014)), os quais verificaram que os estudantes do ensino superior ainda dispõem de baixo nível de conhecimento financeiro.

Ainda com adultos, mas não ligados à universidade, Potrich, Vieira e Kirch (2016), em outro estudo com os habitantes maiores de 18 anos de sete mesorregiões do Estado do Rio Grande do Sul, apontaram que os respondentes do gênero feminino, com filhos, com baixo nível de escolaridade e renda própria são aqueles que mais se enquadram no nível de baixa alfabetização financeira. Esses resultados corroboram os achados de Fernandes, Monteiro e Santos (2012), ao apontarem que as mulheres têm insegurança diante de assuntos relacionados ao mercado financeiro. Em outra perspectiva, Gorla et al. (2016) analisaram os estudantes do ensino médio de 14 escolas da rede pública de Blumenau e região. Mostram que não há uma educação financeira efetiva nos mais de 1,9 mil alunos entrevistados. Somente $4,85 \%$ deles realizam algum tipo de investimento e poupam algum recurso somente se necessário.

Os estudos analisados evidenciaram algumas variáveis que impactam o conhecimento financeiro, como: o gênero, a idade, a renda e o grau de escolaridade do indivíduo e de seus pais. Quanto ao gênero, esses estudos identificaram que o gênero feminino apresenta maior propensão a deter baixo nível de conhecimento financeiro (Potrich et al., 2015). Já o perfil financeiro do gênero masculino indica características de educação financeira, apresentando melhor comportamento na administração de recursos financeiros (Potrich, Vieira \& Paraboni, 2013; Gorla et al., 2016). Já em relação à idade, estudantes na faixa etária de 21 a 22 anos apresentam maiores índices de alfabetização financeira (Potrich et al., 2013). Quanto à influência da renda no conhecimento financeiro, verificouse que os indivíduos com maior renda detêm maior conhecimento financeiro, bem como as famílias com maior renda têm maior nível de educação financeira (Potrich et al., 2013; Gorla et al., 2016). Por fim, a escolaridade dos pais também importa. Os jovens que têm pais que já concluíram o ensino superior apresentam maior domínio e segurança sobre finanças (Verdinelli, Lizote \& Olivares, 2014).

Em outros países, os resultados são similares. Falahati, Sabri e Paim (2012) acessaram 700 universitários de cinco universidades da Malásia e, dentre os achados, verificou-se que os pais são os principais responsáveis por incentivá-los, desde a infância, ao convívio com situações financeiras. Na Corea, alguns estudos também mostram casos de baixo domínio de finanças (ex. Hahn, Jang \& Park, 2014). Na Alemanha e Letônia, Mavlutova, Sarnovics e Armbruster (2015) constataram um nível médio de alfabetização financeira entre 120 alunos alemães e 500 letões. O questionário cobria temáticas de poupança, conhecimento de mercado financeiro, diversificação de risco, e juros para identificar o que é ser educado financeiramente. Entretanto, não relacionaram se os alunos já tinham que deter aptidões em matemática, cognitivas ou lógicas para responder as questões propostas.

\subsection{Influência das habilidades matemáticas}

Além das características demográficas, as habilidades matemáticas podem afetar o desenvolvimento da educação financeira. Estudantes universitários de três instituições norte-americanos que a capacidade em matemática, bem como a confiança e conhecimentos matemáticos são determinantes na alfabetização financeira (Bahrani, Holder \& Patel, 2017).

Refletir e decidir em termos de finanças pessoais, demanda dos alunos do ensino médio competências adquiridas no ambiente familiar ou de relações pessoais, que sejam de interesse pessoal, que tenham motivação, ou pela educação oferecida em disciplinas especificas na escola, ou em atividades complementares e cursos sobre o tema. Mas o quanto tais informações são realmente assimiladas e articuladas por eles depende de raciocínio lógico, operações básicas, e conhecimento de juros (Mancebón, Embún \& Sancho, 2016). Essas habilidades são necessárias nas diversas situações vivenciadas que contextualizam a decisão financeira. Assim, o conhecimento financeiro possui forte correlação com conceitos, definições, situações teóricas sobre custo de oportunidade, inflação, poder de compra, risco e retorno, diversificação, racionalização, aptidões em habilidades básicas de matemática e raciocínio lógico (Hilgerth, Hogarth \& Beverly, 2003). 
Estudos empíricos no tema já mostra este efeito. Bahrani, Holder e Patel (2017) identificaram que aqueles com maior nível de conhecimento em operações matemáticas básicas tendem a assumirem maiores riscos e optam por maior nível de planejamento, quando comparados com os estudantes baixos níveis de confiança e aptidões matemáticas.

Na Espanha, Bover, Hospido e Villanueva (2015) verificaram o efeito da adoção de um curso de alfabetização financeira baseado em conceitos de juros, inflação, operações matemáticas, racionalidade na tomada de decisões de 78 escolas secundárias públicas e privadas. Os autores aplicaram um questionário ao término do curso e verificaram o aumento no acerto de questões relacionadas a consumo, inflação, risco e diversificação. Diante disso, os autores sugerem que operações básicas de matemática sejam desenvolvidas desde os primeiros anos do ensino médio.

Em Lusradi et al. (2009), a habilidade matemática e a aritmética foram medidas pelo próprio questionário aplicado. O teste de habilidade foi extraído do Armed Services Vocational Aptitude Battery (ASVAB), aplicado para entrada nas forças armadas norte-americanas. Dois blocos do teste captam raciocínio aritmético e conhecimento em matemática. A educação financeira é captada por questões que envolvem conceitos financeiro básicos, em temas como taxas de juros, inflação e diversificação de risco. Os resultados mostraram que tais habilidades impactam na capacidade de jovens responderem questões sobre diversificação de risco, taxa de juros e inflação. Na mesma linha, Japelli e Padula (2013) identificam uma relação direta entre habilidades matemática (neste caso medidas pelo teste PISA) e educação financeira.

Para uma amostra de 865 estudantes mexicanos em escolas de ensino médio público e privado na Cidade do México, Amezcua e Everardo (2017) confirma a influência da matemática na alfabetização financeira. Os resultados evidenciaram que a baixa instrução matemática culmina em barreiras no processamento de informações no tocante à aversão ao risco, perder melhores oportunidades, tal como, a tomar empréstimos com taxas de juros mais elevadas. Neste estudo, a habilidade matemática foi captada pelo instrumento aplicado. A explicação dada é que as habilidades matemáticas estimulariam o pensamento lógico, a capacidade de resolver problema, afetando positivamente o planejamento a longo prazo. No estudo, apenas $6,6 \%$ da amostra acertou todas as assertivas propostas de finanças, demonstrando um baixo conhecimento financeiro e baixo domínio sobre conteúdos matemáticos.

\section{PROCEDIMENTOS METODOLÓGICOS}

Foi feito um levantamento com a adaptação de questionários aplicados na literatura prévia, similares em sua origem na Health and Retirement Survey (HRS) de 2004. O estudo de Lusradi et al. (2009) é um exemplo da escala aplicada. No Brasil, instrumento similar foi aplicado por Potrich et al. (2013) e Potrich et al. (2015). Partimos da tradução utilizada por estes autores para formação do questionário aplicado à presente pesquisa. $\mathrm{O}$ questionário tem duas seções, a primeira apresentou questões referentes à caracterização do respondente (Apêndice A) e a segunda com 13 questões de múltipla escolha para captar a condição dos jovens acessar o conhecimento financeiro que nas temáticas de juros, valor do dinheiro no tempo e investimentos (Quadro 2). Tais temáticas aparecem na vida cotidiana, e representam o ferramental que eles terão para decidir sobre poupança, renda e consumo. Cada uma das questões da segunda seção tem uma maior ou menor nível de exigência de habilidades e conceitos demandados (Quadro 2).

O uso das questões já aplicadas em Potrich et al. (2013) e Potrich et al. (2015) procura gerar certa comparabilidade nos estudos nacionais no tema. Contudo diferente desses autores, trazemos a reflexão sobre as habilidades necessárias para a chamada educação financeira (financial literacy na literatura internacional).

As questões de conhecimento financeiro, presentes também em Lusradi et al. (2009), Japelli e Padula (2013) e Amezcua e Everardo (2017), demandam diferentes habilidades para que as respostas corretas sejam acessadas. O que já foi comprovado pelos citados autores. Em Lusradi et al. (2009) o teste ASVAB aplicado, divide as habilidades dos estudantes em raciocínio aritmético e conhecimento em matemática. Porém, os autores não associam o tipo de habilidade demandada em cada questão de conhecimento financeiro a ser respondido.

Aqui sugerimos uma associação entre as habilidades demandadas em cada questão, com a temática de cada questão (a mesma presente em Lusradi et al. 2009). O Quadro 2, classifica as 13 questões segundo as habilidades (álgebra, raciocínio aritmético e conceitos de finanças e economia) para que os jovens possam responder corretamente as questões. Em adultos estes conceitos estão mais consolidados pela formação em diversas disciplinas ao longo dos estudos, ou mesmo pela vivência cotidiana. No caso de adolescentes é menos provável, o que poderia explicar o baixo nível de educação financeira já encontrado nos estudos de Potrich et al (2013, 2015), Lusradi et al. (2009), Japelli e Padula (2013); e Amezcua e Everardo (2017). 
Q1- Suponha que você tenha R $\$ 100,00$ em uma conta poupança a uma taxa de juros de $10 \%$ ao ano. Depois de 5 anos, qual o valor que você terá na poupança? Considere que não tenha sido depositado e nem retirado dinheiro. Mais do que RS 150,00 , Menos do que R\$150,00, Exatamente a R\$150,00, Não sei.

Q2- Suponha que José herde R \$10.000,00 hoje e Pedro herde R \$10.000,00 daqui a 3 anos. Devido à herança, quem ficará mais rico? José, São igualmente ricos, Pedro, Não sei.

Q3- Imagine que a taxa de juros incidente sobre sua conta poupança seja de 6\% ao ano e a taxa de inflação seja de $10 \%$ ao ano. Após 1 ano, o quanto você será capaz de comprar com o dinheiro dessa conta? Mais do que hoje, Menos do que hoje, Exatamente o mesmo, Não sei.

Q4- Suponha que no ano de 2016 sua renda dobrará e os preços de todos os bens também dobrarão. Em 2016, o quanto você será capaz de comprar com a sua renda? Mais do que hoje, Menos do que hoje, Exatamente o mesmo, Não sei.

Q5- Considerando-se um longo período de tempo (ex.: 10 anos), qual ativo, normalmente, oferece maior retorno? Poupança, Títulos públicos, Ações, Não sei.

Q6- Normalmente, qual ativo apresenta as maiores oscilações ao longo do tempo? Poupança, Títulos públicos, Ações, Não sei.

Q7- Quando um investidor distribui seu investimento entre diferentes ativos, o risco de perder dinheiro: Aumenta, Permanece inalterado, Diminui, Não sei.

Q8- Um empréstimo com duração de 15 anos normalmente exige pagamentos mensais maiores do que um empréstimo de 30 anos, mas o total de juros pagos ao final do empréstimo será menor. Verdadeira, Falsa, Não sei.

Q9- Suponha que você realizou um empréstimo de R $\$ 10.000,00$ para ser pago após um ano e o custo total com os juros é $\mathrm{R} \$ 600,00$. A taxa de juros que você irá pagar nesse empréstimo é de $0,3 \%, 6 \%, 0,6 \%, 3 \%$, Não sei.

Q10- Suponha que você viu o mesmo televisor em duas lojas diferentes pelo preço inicial de R\$1.000.00. A loja A oferece um desconto de $\mathrm{R} \$ 150,00$, enquanto a loja B oferece um desconto de $10 \%$. Qual é a melhor alternativa? Comprar na loja A (desconto de R\$150,00), Comprar na Loja B (desconto de 10\%), Não sei.

Q11- Imagine que cinco amigos recebem uma doação de R $\$ 1.000,00$ e precisam dividir o dinheiro igualmente entre eles. Quanto cada um vai obter? R\$ 100,00, R\$ 1.000,00, R\$ 200,00, R\$ 5.000, Não sei.

Temáticas

Juros e desconto Dinheiro no tempo

Investimento

\section{Álgebra}

Raciocínio

Aritmético

Raciocínio

Aritmético

Raciocínio

Aritmético

Finanças (Risco/Retorno)

Finanças

(Risco/Retorno)

Finanças

(Risco/Retorno)

Álgebra

Álgebra

Álgebra

Finanças

Q12- Um investimento com alta taxa de retorno terá alta taxa de risco. Essa afirmação é: Verdadeira, Falsa, Não sei.

Q13- Quando a inflação aumenta, o custo de vida sobe. Essa afirmação é: Verdadeira, Falsa, Não sei.

Quadro 2. Assertivas apresentadas no Questionário, tipo de habilidade demandada e temáticas

Fonte: Organizado pelas autoras.

Nota: Todas as questões demandam algum tipo de conhecimento mínimo de finanças ou economia, mas algumas pedem conhecimento mais específico como de Risco e Retorno de títulos e de inflação. Outras além de conhecimento mínimo pedem uso de álgebra simples (operação matemática binária) para chegar a resposta, e outras pedem uso de raciocínio aritmético. 
Apesar da escolha parecer problemática quando os respondentes são adolescentes, o uso de tais questões (normalmente aplicadas em adultos) dá a oportunidade de observar as lacunas a serem preenchidas com o tempo. Contudo, isso não significa que os jovens não consigam tomar decisões mais simples de consumo responsável e poupança naquele momento da vida, que requerem menor conhecimento formal em finanças e economia.

Na aplicação do questionário, o estudante deveria analisar os itens propostos e indicar uma única alternativa correta ou se desconhecia a resposta. A soma dos pontos para questões corretas é o nível de conhecimento atribuído ao estudante. Para os testes estatísticos foram utilizadas a médias de acertos individuais dos participantes. Destacase que as perguntas foram apresentadas na mesma ordem do Quadro 2, sem randomização da ordem das questões, portanto eventuais efeitos de aprendizagem ou influência das perguntas iniciais sobre as precedentes não está controlado neste estudo.

A coleta dos dados ocorreu em oito escolas de ensino médio na região metropolitana de Uberlândia em Minas Gerais. A Cidade de Uberlândia, localizada no triângulo mineiro, atualmente com cerca de 680 mil habitantes, é a $2^{\circ}$ maior cidade do estado de Minas Gerais. A cidade é altamente industrializada e é importante centro logístico do país. Atualmente a região tem um IDH de 0.789 (Instituto Brasileiro de Geografia e Estatística, 2017).

Sua rede de ensino em 2017 era formada por 28 escolas de ensino médio, com alunos de 15 a 17 anos, cerca de 12,2 mil alunas e 11 mil alunos. Em 2017, a nota média das escolas de Uberlândia foi de 280,4 pontos em Matemática e 276,34 em Linguagens, pelo Sistema Nacional da Educação Básica (SAAB). Este exame é realizado pelo Instituo Nacional de Estudos e Pesquisas Educacionais Anísio Teixeira (INEP), ele é utilizado como um diagnóstico da educação brasileira e busca avaliar o desempenho e a qualidade do ensino ofertado para a $5^{\circ}$ ano, $9^{\circ}$ ano e os três anos do ensino médio, mensurando o nível de conhecimento na área de matemática e língua portuguesa por meio da aplicação de um caderno de questões direcionadas a tais áreas de conhecimento (INEP, 2017). Em termos de comparação, a média estadual das escolas de Uberlândia foi de 271,59 em Matemática e 268,49 em Linguagens (INEP, 2017). As escolas participantes do estudo e suas médias no Exame Nacional do Ensino Médio (ENEM) são apresentadas no quadro 3.

\begin{tabular}{rcccccc}
\hline Escolas & $\begin{array}{c}\text { Oferece } \\
\text { merenda? }\end{array}$ & $\begin{array}{c}\text { Região } \\
\text { da cidade }\end{array}$ & $\begin{array}{c}\text { Número de } \\
\text { funcionários }\end{array}$ & $\begin{array}{c}\text { Número de } \\
\text { matrículas }\end{array}$ & $\begin{array}{c}\text { Matemática } \\
\text { (média no ENEM) }\end{array}$ & $\begin{array}{c}\text { Linguagens } \\
\text { (média no ENEM) }\end{array}$ \\
\hline E1 & Sim & Sul & 75 & 500 & 487 & 498 \\
E2 & Sim & Centro & 116 & 1046 & 508 & 518 \\
E3 & Sim & Centro & 121 & 688 & 453 & 490 \\
E4 & Sim & Norte & 86 & 562 & 512 & 517 \\
E5 & Sim & Sul & 120 & 793 & 494 & 505 \\
E6 & Sim & Leste & 106 & 817 & 520 & 524 \\
E7 & Sim & Oeste & 130 & 700 & 458 & 488 \\
E8 & Sim & Oeste & 73 & 889 & 479 & 498 \\
\hline
\end{tabular}

Quadro 3. Características das escolas de origem dos respondentes

Fonte: INEP (2017).

Nota: Escolas: Escola Estadual Alda Mota Batista (E1), Estadual Américo René Gianetti (E2), Escola Estadual Bueno Brandão (E3), Escola Estadual Guiomar de Freitas Costa- Polivalente (E4), Escola Estadual do Parque São Jorge (E5), Escola Estadual Segismundo Pereira (E6), Escola Estadual Teotônio Vilela (E7) e Escola Estadual Sergio de Freitas Pacheco (E8).

Todas as escolas são públicas, gratuitas e a matrícula é anual, e oferecem merenda aos alunos. A maioria dos jovens matriculados no ensino médio cursou os períodos anteriores também em escola pública. A delimitação da população é não probabilística, selecionada por conveniência devido ao não acesso a todas as instituições educacionais.

Para a aplicação do questionário, contou-se com o apoio dos coordenadores das escolas, tendo sido solicitada a autorização do professor para que os estudantes participantes respondessem ao questionário em sala de aula. Optou-se por seis salas de cada instituição, sendo duas turmas de cada série do ensino médio $\left(1^{\circ}, 2^{\circ}\right.$ e $3^{\circ}$ ano). Antes da aplicação do questionário, realizou-se um pré-teste, utilizando o instrumento de pesquisa com um grupo de dez alunos do segundo ano do ensino médio verificando a compreensibilidade das assertivas, foram realizados ajustes. 
A amostra final da pesquisa é de 976 estudantes matriculados entre o primeiro e terceiro ano do ensino médio no segundo semestre de 2016. Os questionários incompletos não foram descartados da amostra, foram usados para alguns testes cujos dados foram informados pelos alunos. Assim, a amostra sofreu variação no decorrer da aplicação dos testes propostos para a análise de resultados que envolveu gênero, pretensão para ingressar no curso superior, período do ensino médio, idade, renda familiar e escolaridade dos pais.

Os respondentes são jovens matriculados do ensino médio, em grande parte matriculados no segundo ano (41,8\%), jovens de 15 a 17 anos (84,0\%), cuja renda familiar está entre 1 e 2 salários mínimos (40,8\%), equilibrados entre gênero declarado por eles entre feminino e masculino. A maioria $(85,3 \%)$ planeja continuar os estudos no ensino superior. A escolaridade dos pais varia entre fundamental incompleto ou analfabeto (23,3\% pai e 20,5\% mãe), ensino médio completo (27,9\% pai e 31,19\% mãe), e formações superiores.

A Tabela 1 apresenta os resultados descritivos relacionando o tipo de questão e o percentual de acertos e erros para os grupos gênero, renda familiar e escolaridade dos pais. Os dados descrevem as questões separadas por assunto: 'Juros e descontos', 'Dinheiro no tempo' e 'Investimentos'. As questões 1 e 2 talvez por serem o início de um questionário tenham tido baixa taxa de acertos de forma geral. O conhecimento específico de finanças colocado no grupo de questões 5 a 8 pode ter afetado a baixa taxa de acertos. Observa-se visualmente diferenças na taxa de acertos para os grupos comparados por gênero, renda familiar e escolaridade dos pais.

Tabela 1. Acertos das questões nos 3 assuntos, por Gênero e Renda Familiar e Escolaridade dos pais

\begin{tabular}{|c|c|c|c|c|c|c|}
\hline \multirow{2}{*}{ Questões } & \multicolumn{2}{|c|}{ Gênero } & \multicolumn{2}{|c|}{$\begin{array}{c}\text { Renda Familiar } \\
\text { (apenas faixas extremas) }\end{array}$} & \multicolumn{2}{|c|}{$\begin{array}{l}\text { Escolaridade dos pais } \\
\text { (apenas faixa extremas) }\end{array}$} \\
\hline & Feminino & Masculino & $\begin{array}{c}\text { Até } 2 \text { salários } \\
\text { mínimos }\end{array}$ & $\begin{array}{c}\text { Acima de } 4 \\
\text { salários mínimos }\end{array}$ & $\begin{array}{c}\text { Fundamental } \\
\text { incompleto }\end{array}$ & $\begin{array}{l}\text { Superior } \\
\text { completo }\end{array}$ \\
\hline \multicolumn{7}{|c|}{ Assunto: Juros e desconto } \\
\hline Q1 & 18,31 & 27,37 & 21,37 & 25,32 & 20,54 & 28,13 \\
\hline Q3 & 36,81 & 44,18 & 38,04 & 45,57 & 34,82 & 59,38 \\
\hline Q9 & 46,26 & 50,43 & 38,63 & 55,06 & 43,75 & 53,13 \\
\hline Q10 & 58,46 & 64,22 & 57,06 & 68,35 & 59,83 & 84,38 \\
\hline Média & 39,96 & 46,55 & 38,77 & 48,57 & 39,73 & 56,25 \\
\hline \multicolumn{7}{|c|}{ Assunto: Dinheiro no tempo } \\
\hline Q2 & 24,21 & 25,86 & 23,14 & 25,32 & 24,11 & 28,13 \\
\hline Q4 & 43,50 & 45,91 & 39,22 & 46,20 & 39,29 & 59,38 \\
\hline Q11 & 66,93 & 76,72 & 68,43 & 72,78 & 68,75 & 93,75 \\
\hline Q13 & 65,75 & 69,83 & 63,53 & 68,99 & 65,18 & 93,75 \\
\hline Média & 50,09 & 54,58 & 48,58 & 53,32 & 49,33 & 68,75 \\
\hline \multicolumn{7}{|c|}{ Assunto: Investimento } \\
\hline Q5 & 24,61 & 30,39 & 25,29 & 36,08 & 25,00 & 50,00 \\
\hline Q6 & 35,04 & 49,57 & 37,45 & 52,53 & 41,07 & 78,13 \\
\hline Q7 & 27,56 & 36,42 & 31,18 & 35,44 & 27,68 & 53,13 \\
\hline Q8 & 36,42 & 42,24 & 45,69 & 38,61 & 43,75 & 65,63 \\
\hline Q12 & 50,00 & 56,90 & 52,35 & 53,80 & 49,11 & 68,75 \\
\hline Média & 34,72 & 43,10 & 38,39 & 43,29 & 37,32 & 63,12 \\
\hline Média total & 41,07 & 47,70 & 43,65 & 48,00 & 41,76 & 62,74 \\
\hline
\end{tabular}

Fonte: Elaborado pelas autoras.

Nota: Porcentagem de indivíduos que acertaram cada uma das questões, e a média de acertos dentro de cada assunto. Acertos abaixo de $40 \%$ marcadas em negrito.

As análises a seguir aplicou o teste não paramétrico, Mann-Whitney (MW). A escolha do método deve-se ao fato de a distribuição dos dados coletados não atenderem aos pressupostos de normalidade, adotou-se de testes não paramétricos (Fávero et al.,2009). Foi considerado para as análises um nível de significância de 5\%. 
Para aplicação do teste de Mann-Whitney, afim de analisar duas amostras independentes, as hipóteses foram testadas em relação aos seguintes grupos: 'escolas de origem'; 'gênero', 'idade'; 'renda familiar' e 'escolaridade dos pais.

\section{ANÁLISE E DISCUSSÃo}

O objetivo não é explicar o conhecimento financeiro (pelos acertos das respostas) em função das habilidades matemáticas, como foi o objetivo dos estudos realizados por Lusradi et al. (2009), Japelli e Padula (2013) e Amezcua e Everardo (2017). Mas sim mostrar como as taxas de acertos variam para um mesmo aluno, dependendo das temáticas e habilidades demandadas. Apesar de não evidenciar as relações de causalidade, apresenta-se que para um mesmo aluno, em um mesmo contexto de escola e família, a tendência de acessar determinado conhecimento é maior.

\section{Temáticas, habilidades e escolas de origem}

A Tabela 2 registra os resultados da comparação referente ao conhecimento financeiro por temáticas e habilidades, e ainda compara as escolas com 'Menor ENEN' e 'Maior ENEM'. Em Lusradi et al. (2009), Japelli e Padula (2013) e Amezcua e Everardo (2017) maior raciocínio aritmético e conhecimento em matemática facilitam o acerto de questões sobre diversificação de risco, taxa de juros e inflação.

Tabela 2. Índice de acertos

\begin{tabular}{|c|c|c|c|c|c|c|c|c|}
\hline & \multicolumn{5}{|c|}{ Amostra total } & \multirow{2}{*}{$\begin{array}{l}\text { Menor } \\
\text { ENEN } \\
\text { E3+E7 } \\
\text { Média } \\
\end{array}$} & \multirow{2}{*}{$\begin{array}{l}\text { Maior } \\
\text { ENEM } \\
\text { E4+E6 } \\
\text { Média }\end{array}$} & \multirow{2}{*}{$\begin{array}{c}\text { Teste Mann- } \\
\text { Whitney } \\
\text { p-valor* }\end{array}$} \\
\hline & n & Média & DP & Max. & Min. & & & \\
\hline Geral & 976 & 0,446 & 0,233 & 1,0 & 0,0 & 0,456 & 0,438 & 0591 \\
\hline \multicolumn{9}{|l|}{ Por temática } \\
\hline Juros de descontos & 975 & 0,407 & 0,233 & 1,0 & 0,0 & 0,400 & 0,418 & 0,665 \\
\hline Dinheiro no tempo & 976 & 0,522 & 0,286 & 1,0 & 0,0 & 0,563 & 0,508 & 0,004 \\
\hline Investimento & 976 & 0,406 & 0,274 & 1,0 & 0,0 & 0,414 & 0,396 & 0,420 \\
\hline \multicolumn{9}{|l|}{ Por habilidades } \\
\hline Álgebra & 976 & 0,486 & 0,283 & 1,0 & 0,0 & 0,501 & 0,496 & 0,906 \\
\hline Raciocínio Analítico & 976 & 0,366 & 0,314 & 1,0 & 0,0 & 0,364 & 0,361 & 0,841 \\
\hline Finanças/Economia & 976 & 0,451 & 0,270 & 1,0 & 0,0 & 0,470 & 0,436 & 0,191 \\
\hline & & & & \multicolumn{5}{|c|}{ Comparação de temáticas } \\
\hline & & & & \multicolumn{4}{|c|}{ Dinheiro no tempo $>$ Juros de descontos } & 0,000 \\
\hline & & & & \multicolumn{4}{|c|}{ Dinheiro no tempo $>$ Investimento } & 0,000 \\
\hline & & & & \multicolumn{4}{|c|}{ Juros de descontos $>$ Investimento } & 0,707 \\
\hline & & & & \multicolumn{5}{|c|}{ Comparação de habilidades } \\
\hline & & & & \multicolumn{4}{|c|}{ Álgebra > Raciocínio Analítico } & 0,000 \\
\hline & & & & \multicolumn{4}{|c|}{ Finanças/Economia > Raciocínio Analítico } & 0,000 \\
\hline & & & & \multicolumn{4}{|c|}{ Álgebra > Finanças/Economia } & 0,006 \\
\hline
\end{tabular}

Fonte: Elaborado pelas autoras.

Nota: * Teste a 5\% de significância. Nota: Geral - acertos em todas 13 questões/13, Juros e descontos - acertos nas questões $1,3,9,10 ;$ dinheiro no tempo - acertos nas questões 2,4,11 e 13; investimento - acertos nas questões 5,6,7,8 e 12 . Habilidades matemáticas de Álgebra acertos nas questões 1,9,10 e 11; raciocínio analítico acertos nas questões 2,3 e 4; finanças/economia acertos nas questões 5,6,7,8, 12 e 13 . Respostas "não sei” foram desconsideradas do cálculo. 
O índice de acertos médio para as 3 temáticas em geral é baixo $(0,406 ; 0,407$ e 0,522$)$, cerca de 5 a 6 questões das 13 apresentadas. Não há diferença significativa entre juros e investimento, mas dinheiro no tempo é um conceito relativamente mais fácil de ser acessado. Ou seja, para um mesmo aluno a mesma facilidade ou dificuldade impacta de forma similar as temáticas de juros e investimento. Infere-se que a dificuldade cognitiva de acessar temas abstratos como diversificação de investimentos e juros seja similar para os jovens estudantes. Ainda, tais resultados podem ser consequência também de nenhuma das temáticas ter sido alvo programático de ensino formal na escola. O conceito de dinheiro no tempo talvez por envolver 'inflação' seja algo mais próximo do dia-a-dia dos jovens.

Já para as três habilidades demandadas, o nível de dificuldade é diferente. O teste de média confirma que as questões que exigem habilidades em Álgebra são mais fáceis para esta amostra do que aquelas questões que demandam Finanças/Economia, e estas mais fáceis que as que demandam Raciocínio Analítico. Estes resultados mostram que, se para um mesmo individuo é maior a probabilidade de acerto para questões que demandam uma ou outra habilidade, tais habilidades podem influenciar a educação financeira. Conceitos e entendimentos vivenciados no dia a dia e, que demandem raciocínio analítico, podem ser de difícil processamento. A implicação disso é que o conhecimento financeiro pode esbarrar na falta de habilidades básicas, que não serão desenvolvidas com cursos e cartilhas que passem apenas conceitos de poupança e consumo sustentável. A prática real diária da educação financeira pode não se concretizar.

Os alunos convivem em diferentes grupos sociais na escola, e estes grupos possuem diferentes desempenho médios no ENEM. Comparamos se o desempenho médio do grupo que ele (a) pertence tem alguma influência. Para tanto, comparamos os estudantes das escolas de menor média ENEM, com aqueles das escolas de maior média. Não notamos diferenças entre estes dois grupos, em todos grupos de questões (por temática e por habilidades), exceto para questões de dinheiro no tempo. Interessante notar que os alunos de escolas com menor média tiverem um desempenho melhor aos da escola de maior média ENEM. Não identificou-se uma explicação razoável para esse resultado.

\section{Gênero e idade}

Uma das variáveis mais testadas neste tipo de estudo, sem necessariamente ter uma sustentação para o efeito, é a variável gênero. Na Tabela 3 evidencia-se que o desempenho dos homens é maior em média em todos os grupos de questões, exceto naquelas que envolvem raciocínio analítico. Como tais jovens frequentam as mesmas escolas, a razão para este desempenho superior pode estar na capacidade de assimilar o próprio raciocínio analítico. De qualquer forma, essa capacidade não se converte em melhores respostas nos grupos temáticos.

Tabela 3. Comparação de médias por gênero e idade

\begin{tabular}{ccccccc}
\hline & Homens & Mulheres & $\begin{array}{c}\text { Teste } \\
\text { Mann- } \\
\text { Whitney } \\
\text { p-valor }\end{array}$ & Até 17 anos & $\begin{array}{c}\text { Acima 17 } \\
\text { anos }\end{array}$ & $\begin{array}{c}\text { Teste } \\
\text { Mann- } \\
\text { Whitney } \\
\text { p-valor }\end{array}$ \\
\cline { 2 - 7 } Geral & Média & Média & & Média & média & 0,686 \\
\hline Por temática & 0,477 & 0,410 & $\mathbf{0 , 0 0 0}$ & 0,444 & 0,433 & 0,865 \\
\hline Juros de descontos & 0,445 & 0,373 & $\mathbf{0 , 0 0 0}$ & 0,408 & 0,402 & 0,264 \\
Dinheiro no tempo & 0,545 & 0,501 & $\mathbf{0 , 0 0 0}$ & 0,527 & 0,496 & 0,880 \\
\hline Investimento & 0,447 & 0,366 & $\mathbf{0 , 0 0 0}$ & 0,405 & 0,407 & 0,276 \\
\hline Por habilidades & & & & & 0,465 & 0,227 \\
Álgebra & 0,526 & 0,450 & $\mathbf{0 , 0 0 0}$ & 0,490 & 0,335 & 0,581 \\
\hline Raciocínio Analítico & 0,386 & 0,450 & $\mathbf{0 , 0 0 0}$ & 0,371 & 0,460 & \\
\hline
\end{tabular}

Fonte: Elaborado pelas autoras.

Nota: * Teste a 5\% de significância. Nota: Geral - acertos em todas 13 questões/13, Juros e descontos - acertos nas questões 1,3,9,10; dinheiro no tempo - acertos nas questões 2,4,11 e 13; investimento - acertos nas questões 5,6,7,8 e 12 . Habilidades matemáticas de Álgebra acertos nas questões 1,9,10 e 11; raciocínio analítico acertos nas questões 2,3 e 4; finanças/economia acertos nas questões 5,6,7,8, 12 e 13. Respostas "não sei” foram desconsideradas do cálculo. 
O resultado para esta amostra é similar a alguns estudos que identificaram o nível de conhecimento financeiro para crianças do gênero masculino (Potrich, Vieira e Kirch, 2015), em calculo financeiro (Potrich, Vieira e Paraboni, 2013; Chen e Volpe, 1998) e maior segurança sobre mercado financeiro (Monteiro, Fernandes e Santos, 2011). Mas diferem de estudos como Bahrari, Holder e Patel (2017) e Mancebón, Embún e Sancho (2016).

Já em relação à idade, não encontramos diferenças significativas nos grupos testados. O que difere dos resultados de Gorla et al. (2016) para alunos do ensino médio das escolas públicas de Santa Catarina, em que o domínio financeiro variou com a idade. O resultado pode diferir dos anteriores pois a faixa de idade é centrada em um momento específico do ciclo de vida (15 a 17 anos).

\section{Renda familiar e escolaridade dos pais}

Estudos relacionados ao tema investigam a influência da família. A escolaridade dos pais facilitaria a educação financeira (Verdinelli, Lizote e Olivares, 2014; Vieira, Bataglia e Sereia, 2015) e a atitude e comportamento financeiro (Jorgensen, 2007; Ibrahim, Harun e Isa, 2009). Ainda, a interação com a família facilitaria o conhecimento financeiro (Braido, 2014; Verdinelli et al., 2014; Liao e Cai, 1995).

Comparou-se os extremos da amostra do estudo quanto a renda familiar, a tabela 4 apresenta diferença de média entre conhecimento financeiro testados nos jovens que tem renda familiar menor que 2 salários mínimos ou maior que 4 salários mínimos.

Tabela 4. Comparação de médias por renda familiar

\begin{tabular}{cccc}
\hline & $\begin{array}{c}\text { Até 2 Salários } \\
\text { mínimos }\end{array}$ & $\begin{array}{c}\text { Acima de 4 salários } \\
\text { mínimos }\end{array}$ & $\begin{array}{c}\text { Teste Mann-Whitney } \\
\text { p-valor }\end{array}$ \\
\cline { 2 - 4 } Geral & Média & Média & $\mathbf{0 , 0 0 3}$ \\
\hline Por temática & 0,436 & 0,470 & $\mathbf{0 , 0 4 3}$ \\
\hline Juros de descontos & 0,399 & 0,440 & 0,091 \\
Dinheiro no tempo & 0,522 & 0,526 & $\mathbf{0 , 0 0 7}$ \\
Investimento & 0,396 & 0,450 & 0,067 \\
\hline Por habilidades & & & 0,083 \\
Álgebra & 0,481 & 0,508 & $\mathbf{0 , 0 0 8}$ \\
\hline
\end{tabular}

Fonte: Elaborado pelas autoras.

Nota: * Teste a 5\% de significância. Nota: Geral - acertos em todas 13 questões/13, Juros e descontos - acertos nas questões 1,3,9,10; dinheiro no tempo - acertos nas questões $2,4,11$ e 13 ; investimento - acertos nas questões 5,6,7,8 e 12 . Habilidades matemáticas de Álgebra acertos nas questões 1,9,10 e 11; raciocínio analítico acertos nas questões 2,3 e 4; finanças/economia acertos nas questões 5,6,7,8, 12 e 13. Respostas "não sei” foram desconsideradas do cálculo.

A renda familiar apresentou diferenças significativas para as questões de juros e descontos, investimento e as que envolvem temas de finanças e economia. Naturalmente, nas famílias com maior renda os temas podem ser mais constantes. Contudo, não houve diferença no tema 'dinheiro no tempo', pois como já proposto anteriormente este tema pode ser parte da vida cotidiana de todos eles, quando percebem a questão da inflação em seu consumo.

Por fim, a tabela 5 compara a escolaridade dos pais. Foram rodados dois testes, o primeiro em que pai e mãe não concluíram o fundamental, comparados com famílias em que tanto pai e mãe completaram o ensino superior. E um segundo em que apenas ou o pai ou a mãe concluíram o ensino superior. 
Tabela 5. Comparação de médias por Escolaridade dos Pais

\begin{tabular}{ccccccc}
\hline & $\begin{array}{c}\text { Pai e } \\
\text { mãe tem } \\
\text { fundamental } \\
\text { incompleto }\end{array}$ & $\begin{array}{c}\text { Pai e mãe } \\
\text { concluíram } \\
\text { o nível } \\
\text { superior }\end{array}$ & $\begin{array}{c}\text { Teste } \\
\text { Mann- } \\
\text { Whitney } \\
\text { p-valor }\end{array}$ & $\begin{array}{c}\text { Pai e } \\
\text { mãe tem } \\
\text { fundamental } \\
\text { incompleto }\end{array}$ & $\begin{array}{c}\text { Um dos pais } \\
\text { tem superior } \\
\text { completo }\end{array}$ & $\begin{array}{c}\text { Teste } \\
\text { Mann- } \\
\text { Whitney } \\
\text { p-valor }\end{array}$ \\
\hline Meral & 0,417 & 0,440 & $\mathbf{0 , 0 3 2}$ & 0,417 & 0,469 & $\mathbf{0 , 0 4 4}$ \\
\hline Por temática & & Média & & & & \\
\hline Juros de descontos & 0,397 & 0,608 & $\mathbf{0 , 0 0 2}$ & 0,397 & 0,453 & 0,130 \\
Dinheiro no tempo & 0,493 & 0,467 & 0,732 & 0,493 & 0,531 & 0,242 \\
Investimento & 0,373 & 0,481 & 0,117 & 0,373 & 0,431 & 0,067 \\
\hline Por habilidades & & & & & 0,527 & 0,178 \\
Álgebra & 0,482 & 0,435 & 0,340 & 0,482 & 0,527 & 0,074 \\
Raciocínio Analítico & 0,327 & 0,358 & 0,447 & 0,327 & 0,393 & 0,109 \\
Finanças/Economia & 0,419 & 0,484 & 0,136 & 0,419 & 0,467 & \\
\hline
\end{tabular}

Fonte: Elaborado pelas autoras.

Nota:* Teste a 5\% de significância. Nota: Geral - acertos em todas 13 questões/13, Juros e descontos - acertos nas questões 1,3,9,10; dinheiro no tempo - acertos nas questões 2,4,11 e 13; investimento - acertos nas questões 5,6,7,8 e 12 . Habilidades matemáticas de Álgebra acertos nas questões 1,9,10 e 11; raciocínio analítico acertos nas questões 2,3 e 4; finanças/economia acertos nas questões 5,6,7,8, 12 e 13. Respostas "não sei" foram desconsideradas do cálculo.

Para média geral das respostas, a diferença da formação dos pais importa para os dois testes. Quanto maior formação dos pais, mesmo que apenas um deles tenha concluído o superior, melhor desempenho dos alunos nas questões de conhecimento financeiro.

Contudo, quando se observa por grupos de questões, o fato de apenas um dos pais ter formação superior não é suficiente para construir um outro ambiente para eliminar a diferença. Quando os dois pais não completam o ensino superior, o tema de juros e descontos pode ter mais dificuldade de ser tratado em algumas famílias de menor formação. Não se elimina a hipótese de efeitos cruzados de renda familiar, que podem ter associação com formação dos pais.

Os estudos realizado por Ibrahim, Harun e Isa (2009), Verdinelli et al. (2014), Liao e Cai (1995) identificaram a influência da escolaridade dos pais na educação financeira dos filhos.

\section{CONSIDERAÇÕES FINAIS}

A aprendizagem financeira tem papel fundamental na tomada de decisão no cotidiano do indivíduo (Hall, 2008). As experiências na fase da adolescência, período em que os jovens estão cursando o ensino médio, têm impacto significativo nos padrões de cognição e comportamento na vida adulta (Ward, 1974).

O estudo discute a associação das habilidades matemáticas dos jovens na educação financeira potencial desses jovens (Bahrari et al., 2017; Mancebón et al., 2016). Os resultados indicam que as temáticas e habilidades pesquisadas no presente estudo apresentaram diferenças estatísticas quando comparado com as variáveis relacionadas à gênero, renda familiar e escolaridade dos pais.

Observou-se um baixo nível de conhecimento financeiro captado pelo instrumento aplicado. Os estudantes mostram dificuldades de entendimento de conceitos de juros e descontos, dinheiro no tempo e conceitos de risco e retorno para realização de investimentos. Pelo senso comum colocado nas pesquisas e programas de desenvolvimento de educação financeira, estes jovens terão maior dificuldade em estabelecer um comportamento de consumo responsável e poupança no futuro.

Um dos principais resultados do estudo é evidenciar que os conceitos e raciocínios ao serem aplicados no dia a dia se demandarem raciocínio analítico podem ser de difícil processamento pelo jovens. Mesmo que sejam oferecidos programas ou cartilhas que trabalhem apenas conceitos de poupança e consumo sustentável, o conhecimento financeiro pode não ser efetivamente aplicado pela falta de habilidades básicas de raciocínio. 
Por fim, os estudos correlatos que investigaram universitários e outros jovens matriculados no ensino médio apresentam resultados nem sempre convergentes para a influência das variáveis gênero, idade, renda familiar, escolaridade dos pais no conhecimento financeiro (ex. Costa \& Miranda, 2013; Potrich et al., 2013; Lizote \& Verdinelli, 2014; Verdinelli et al., 2014; Gorla et al., 2016; Potrich et al., 2014). Tais diferenças podem estar associados não apenas à regiões ou amostras, mas também aos questionários utilizados, que podem demandar diferentes habilidades dos jovens pesquisados.

O cenário reforça a importância de investimentos em projetos que visem promover a educação financeira em escolas de ensino básico, conforme proposta da Secretaria de Educação Básica (SEB) iniciada em 2015. O Governo Federal com o lançamento da Estratégia Nacional de Educação Financeira em 2010 (decreto n ${ }^{\circ}$ 7.397/2010) tentou promover nacionalmente um programa de educação financeira de crianças e jovens do ensino fundamental e médio. Na região em análise as iniciativas ainda são isoladas e restritas à algumas escolas atendidas pelo programa (BANCO DO BRASIL, 2010). Tais estratégias poderiam analisar a inclusão compulsória no currículo escolar das escolas públicas noções de finanças pessoais desde os anos iniciais. As ações empreendidas pelo Banco Central e Comissão de Valores Mobiliários precisam ser disseminadas com o propósito de atender um maior número de jovens estudantes.

\section{REFERÊNCIAS}

Amezcua, A. V., \& Everardo, J. A. H. (2017). Financial Literacy and Mathematics: A study among Young Mexican High School Students. Revista Mexicana de Economía Y Finanzas, 12(2), 1-22.

Bahrani, A. A., Holder, K., Buser, W., \& Patel, D. (2017). The Role of Math Confidence in Explaining the Financial Literacy Gender Gap. Anais do 10 American Economic Association, Chicago, United States.

Brasil. (2010). Decreto n. 7.397, de 22 de dez. de 2010. Estratégia Nacional de Educação Financeira - ENEF. Brasília, DF.

Bover, O., Hospido, L., \& Villanueva, E. (2015). The Impact of High School Financial Education on Financial Knowledge, Attitudes and Preferences: Evidence from a Randomized Trial in Spain. IZA Discussion Papers 11265, Institute for the Study of Labor (IZA).

Banco Central (2015). O programa de Educação Financeira do Banco Central. Recuperado em 03 de jan. de 2015 de http://www.bcb.gov.br/?BCEDFIN.

Belás, J., Nguyen, A., Smrčka, L., Kolembus, J., \& Cipovová, E. (2016). Financial Literacy of Secondary School Students. Case Study from the Czech Republic and Slovakia, Economics and Sociology, 9(4), 191-206. DOI: https://doi.org/10.14254/2071-789X.2016/9-4/12

Brasil (2010). Decreto . $^{\circ}$ 7.397, de 22 de dezembro de 2010. Institui a Estratégia Nacional de Educação Financeira - ENEF e dispõe sobre a sua gestão e dá outras providências. Diário Oficial da República Federativa do Brasil, Brasília, DF, p.7, 23 dez. 2010. Seção 1.

Clancy, M., Weiss, M. G., \& Schereider, M. (2001). Financial Education and Savings Outcomesin Individual Development Accounts. University Library of Munich, Germany.

Confederação Nacional do Comércio de Bens, Serviços e Turismo (2016). O perfil do endividamento das famílias brasileiras em 2016. Recuperado em 01 fev. 2017 de http://cnc.org..br/sites/default/files/arquivos/perfil_de_ endividamento_das_familias_brasileiras_em_2016_0.pdf.

Costa, C. M., \& Miranda, C. J. (2013). Educação financeira e a determinação da taxa de poupança. Revista de Gestão, Finanças e Contabilidade, 3(3), 309- 325.

Fávero, L. P., Belfiore, P.; Silva, F. L., \& Chan, B. L. (2009). Análise de dados: modelagem multivariada para tomada de decisões. 2. ed. Rio de Janeiro: Elsevier.

Falahati, L., Sabri, M. F., \& Paim, L. H. J. (2012). Assessment a model of Financial Satisfaction Predictors: Examining the Mediate Effect of Financial Behavior and Financial Strain. World Applied Sciences Journal, 20(2), 190-197. DOI: https://doi.org/10.5829/idosi.wasj.2012.20.02.1832.

Fernandes, D., Lynch, J. G., \& Netemeyer, R. G. (2014). Financial Literacy, Financial Education and Downstream Financial Behavior. Management Science, 60(8), 1861- 1883. DOI: https://doi.org/10.1287/mnsc.2013.1849.

Fernandes, B. V. R., Monteiro, D. L., \& Santos, W. R. (2012). Finanças Pessoais: Um Estudo dos seus Princípios Básicos com Alunos da Universidade de Brasília. Accouting and Management, 6(6), 9-28. 
Grimes, P. W., Rogers, K. E., \& Smith, R. C. (2010). High School Economic Education and Access to Financial Services. The Journal of consumer affairs, 44(2), 317-335. DOI: https://doi.org/10.1111/j.17456606.2010.01171.x.

Gorla, M. C., Magro, C. B. D., Silva, T. P., \& Nakamura, W.T. (2016). A Educação Financeira dos Estudantes do Ensino Médio de Rede Pública segundo aspectos Individuais, Demográficos e de Socialização. Anais Congresso de Controladoria e Contabilidade, São Paulo, Brasil, 16.

Hall, M. K. (2008). The Importance of Financial Literacy. Bulletin, 1(1), 12-18.

Hahn, J., Jang, K., \& Park, H. J. (2014). Financial Literacy of Korean High School Students. Anais da 2014 Annual Meeting, USA, 2.

Hilgerth, M. A., Horgarth, J. M., \& Beverley. (2003). Household Financial Management: The Connection between Knowledge and Behavior. Federal Reserve Bulletin, 309-322.

Ibrahim, D.M, Harun, R., \& Isa, Z. M. (2009). A study on financial literacy of Malaysian Degree Students. CrossCultural Communication, 5(4), 51-59. DOI: http://dx.doi.org/10.3968/j.ccc.1923670020090504.006.

Instituto Brasileiro de Geografia e Estatística. (2017). Uberlândia. Recuperado em 28 novembro, de https:// cidades.ibge.gov.br/brasil/mg/uberlandia/panorama.

Instituto Brasileiro de Geografia e Estatística. (2017). IDEB. Recuperado em 29 novembro, de http://portal.inep. gov.br/web/guest/educacao-basica/ideb/resultados.

Instituto Brasileiro de Geografia e Estatística. (2017). Sinopses Estatísticas da Educação Básica. Recuperado em 29 novembro, de http://portal.inep.gov.br/web/guest/sinopses-estatisticas-da-educacao-basica.

Instituto Nacional de Estudos e Pesquisas Educacionais Anísio Teixeira. (2015). Pisa no Brasil. Recuperado em 29 de novembro, de http://portal.inep.gov.br/pisa-no-brasil.

Instituto Nacional de Estudos e Pesquisas Educacionais Anísio Teixeira. (2017). Sistema de Avaliação da Educação Básica. Recuperado em 27 novembro, de http://portal.mec.gov.br/docman/agosto-2018-pdf/94181saeb-2017-versao-ministro-revfinal-1/file.

Jappeli, T., \& Padula, M. (2013). Investment in financial literacy and saving decisions. Journal of Banking and Finance, 37 (8), 2779-2792. DOI: https://doi.org/10.1016/j.jbankfin.2013.03.019.

Jobim, S. S. S., \& Losekann, V. L. (2015). Alfabetização financeira: mensuração do comportamento e conhecimento financeiros dos universitários da universidade da região da campanha, Rio Grande do Sul. Revistas Sociais e Humanas, 28(69), 125-139. DOI: http://dx.doi.org/10.5902/2317175818835.

Liao, T. F., \& Cai, Y. (1995). Socialization life situations and gender role attitudes regarding the family among white American women. Sociological Perspectives, 38(2), 241-260. DOI: http://dx.doi.org/10.2307/1389292.

Lizote, S. A., Simas, J., \& Lanas, J. (2012). Finanças Pessoais: um estudo envolvendo os alunos de ciências contábeis de uma instituição de ensino superior de Santa Catarina. Revista da Unifebe, 1(19), 71-85.

Lizote, S. A., \& Verdinelli, M. A. (2014). Educação Financeira: um estudo das associações entre o conhecimento sobre finanças pessoas e as características dos estudantes universitários do curso de Ciências Contábeis. Anais Congresso Usp de Controladoria e Contabilidade, São Paulo, Brasil.

Lusardi, A., \& Mitchell, O. S. (2014). The Economic Importance of Financial Literacy: Theory and Evidence, Journal of Economic Literature. American Economic Association, 52(1), 5-44. DOI: http://dx.doi.org/10.3386/ w18952

Lusardi, A., Mitchell, O. S., \& Curto, V. (2009). Financial Literacy Among the Young. Journal of Consumers Affairs, 44 (2), 358-380. DOI: http://dx.doi.org/10.3386/w15352.

Mancebón, M. J., Embún, D. P. X, Sancho, J. M. G. (2016) Financial literacy, mathematical performance and school ownership. Anais do 1 Economics Statistic and Econometrics of Education, Lisbon, Portugal.

Mavlutova, I., Sarnovics, A., \& Armbruster, C. (2015). Financial literacy of young generation in changing european environment: evidence from germany and latvia. Anais do Management, Knowledge and Learning, Bari, Italy. 
Ministério da Educação (2006). Orientações curriculares para o ensino médio: Ciências da Natureza, Matemática e suas Tecnologias. Recuperado em 27 jan. 2017 de http://portal.mec.gov.br/seb/arquivos/pdf/book volume_02_internet.pdf.

Moore, D. (2003). Survey of Financial Literacy in Washington State: Knowledge, behavior, Attitudes, and Experiences.Olympia, WA : Washington State Dept. of Financial Institutions.

Organização para a Cooperação e Desenvolvimento Econômico. (2005). Improving Financial Literacy: Analysis of issues and policies. Recuperado em 02 jan. 2017 de http://www.oedc.org/http://www.oecd.org/finance/ financialeducation/improvingfinancialliteracyanalysisofissuesandpolicies.htm.

Opletalová, A. (2015). Financial education and financial literacy in the Czech education system. Social and Behavioral Sciences, 171(1), 1176-1184. DOI: https://doi.org/10.1016/j.sbspro.2015.01.229.

Potrich, A. C., Vieira, K. M. \& Kirch, G. (2015). Determinantes da Alfabetização Financeira: análise da influência de variáveis socioeconômicas e demográficas. Revista de Contabilidade \& Finanças, 26 (69), 362-377. DOI: http://dx.doi.org/10.1590/1808-057x201501040.

Potrich, A. C., Vieira, K. M. \& Kirch, G. (2016). Você é alfabetizado financeiramente? Descubra no termômetro de alfabetização financeira. Revista de Administração e Contabilidade da Unisinos, 13(2), 153-170. DOI: http:// dx.doi.org/10.4013/base.2016.132.05

Potrich, A. C., \& Ceretta, P. S. (2013). Nível de alfabetização financeira dos estudantes universitários: afinal, o que é relevante? Revista Eletrônica de Ciência Administrativa, 12(3), 315-334.

Potrich, A. C., \& Paraboni, A. L. (2013). O que influencia a alfabetização financeira dos estudantes universitários? Anais Seminários em Administração, São Paulo, Brasil.

Remund, D. L. (2010). Financial Literacy Explicated: The Case for a Clearer Definition in an Increasingly Complex Economy. Journal of Consumer Affairs, 44 (2), 276-294. DOI: https://doi.org/10.1111/j.17456606.2010.01169.x.

Savoia, J. R. F., Saito, A. T. \& Santana, F. A. (2007). Paradigmas da educação financeira no Brasil. Revista de Administração Pública, 41 (6), 1111-1141. DOI: http://dx.doi.org/10.1590/S0034-76122007000600006.

Serviço de Proteção ao Crédito. (2016). Carro, viagens e faculdade são principais itens que os jovens desejam mas não compram por falta de crédito, indica SPC Brasil. Recuperado em 01 fev. $2017 \mathrm{em} \mathrm{https://www.spcbrasil.}$ org.br/imprenssa/noticia/2458.

Silva, T. P., Magro, B. D. C., Gorla, M. C., \& Toshiro, N. W. (2017). Financial education level of high school students and its economic reflectons, Revista de Administração-RAUSP, 52 (3), 285-303. DOI: https://doi. org/10.1016/j.rausp.2016.12.010.

Vargas, G. B. A. (2015). Importância da Educação Financeira no Brasil. Instituto Brasileiro de Executivos de Finanças do Espírito Santo. Recuperado em 3 de janeiro, 2016, de http://ibefes.org.br/a-importancia-daeducacao-financeira-no-brasil/.

Vieira, S. F. A., Bataglia, R. T. M., \& Sereia, V. J. (2011). Educação financeira e decisões de consumo, investimentos e poupança: uma análise dos alunos de uma universidade pública. Revista de Administração da UNIMEP, 9 (3), 61 -86. DOI: 10.15600/1679-5350/rau.v9n3p61-86.

Ward, S. (1974). Consumer Socialization. Journal of Consumer Research, 1 (2), 1-14.

Xiao, J. J., Noring, F. E., \& Anderson, J. G. (1995). College student' attitudes towards credit cards. Journal of Consumer Studies and Home Economics, 19 (1), 155-174. DOI: https://doi.org/10.1111/j.1470-6431.1995. tb00540.x.

\section{Como citar este artigo}

Silva, M. A. da, Leal, E. A., \& Araújo, T. S.(2018). Habilidades matemáticas e o conhecimento financeiro no ensino médio. Revista de Contabilidade e Organizações, 12:e147269. DOI: http://dx.doi.org/10.11606/ issn.1982-6486.rco.2018.147269 


\section{APÊNDICE A - Questionário}

Convidamos você para participar da pesquisa, informamos que em momento nenhum da pesquisa terá a identificação do participante, os dados serão analisados de forma agregada.

\section{$1^{\mathrm{a}}$ parte: Caracterização dos respondentes}

Sexo:

\section{Idade:}

( ) Masculino

( ) Feminino
( ) menos de 15 anos
( ) de 15-17 anos
( ) de 18-20 anos
( ) mais de 20 anos

\section{Está cursando :}

\section{Pretende ingressar no Ensino Superior:}
( ) $1^{\circ}$ ano do Ensino Médio
( ) $2^{\circ}$ ano do Ensino Médio
( ) $3^{\circ}$ ano do Ensino Médio

\section{Escolaridade da Mãe:}

( ) Superior completo

( ) Ensino médio completo

( ) Fundamental completo

( ) Analfabeto

( ) Superior incompleto

( ) Ensino médio incompleto

( ) Fundamental incompleto

\section{Renda Familiar:}

( ) até 1 salário mínimo (até R $\$ 880,00$ )

( ) de 2 a 4 salários mínimos (de R\$1.761,00 a R\$3.520,00)

( ) de 6 a 8 salários mínimos (de $\mathrm{R} \$ 5.281,00$ a R $\$ 7.040,00$ )
( ) de 1 a 2 salários mínimos (de $\mathrm{R} \$ 881,00$ a $\mathrm{R} \$ 1.760,00$ )

( ) de 4 a 6 salários mínimos (de $\mathrm{R} \$ 3.521,00$ a $\mathrm{R} \$ 5.280,00$ )

( ) acima de 8 salários mínimos (acima de $\mathrm{R} \$ 7.041,00$ )

\section{( ) Sim. Qual curso? \\ ( ) Não}

\section{Escolaridade do Pai:}
( ) Superior completo
( ) Superior incompleto
( ) Ensino médio completo
( ) Ensino médio incompleto
( ) Fundamental completo
( ) Fundamental incompleto 